\title{
Low-intensity Pulsed Ultrasound Improves Muscle Atrophy in Hindlimb Unloading Rats and its Metabolic Mechanism
}

Lijun Sun ( $\sim$ sunlijun@snnu.edu.cn )

Shaanxi Normal University

Shasha An

Shaanxi Normal University

Zhihao Zhang

Shaanxi Normal University

Yaling Zhou

Shaanxi Normal University

Zhanke Ma

Shaanxi Normal University

Xiushan Fan

Shaanxi Normal University

Liang Tang

Shaanxi Normal University

Jianzhong Guo

Shaanxi Normal University

\section{Research}

Keywords: Muscle atrophy, Low intensity pulsed ultrasound, myostatin, Metabonomics

Posted Date: April 6th, 2021

DOl: https://doi.org/10.21203/rs.3.rs-389558/v1

License: (1) (1) This work is licensed under a Creative Commons Attribution 4.0 International License. Read Full License 


\section{Abstract}

Low-intensity pulsed ultrasound (LIPUS) has been proved to promote the proliferation of myoblast C2C12. However, whether LIPUS can effectively prevent muscle atrophy has not been clarified, and if so, what is the possible mechanism. Myostatin (MSTN) is a negtive regulator of skeletal muscle, and inhibition of its expression has a positive effect on the growth and development of skeletal muscle.The aim of this study is to evaluate the effects of LIPUS on muscle atrophyin hind limb unloading rats, and explored the mechanisms. The rats were randomly divided into four groups: normal control group (NC), hind limb unloading group (UL), hind limb unloading plus $30 \mathrm{~mW} / \mathrm{cm}^{2}$ irradiation group (UL +30 $\mathrm{mW} / \mathrm{cm}^{2}$ ), hind limb suspension plus $80 \mathrm{~mW} / \mathrm{cm}^{2}$ irradiation group $\left(\mathrm{UL}+80 \mathrm{~mW} / \mathrm{cm}^{2}\right)$. The rats were suspended or/and treated with LIPUS for $20 \mathrm{~min} / \mathrm{d}$ for 28 days. C2C12 cells were exposed to LIPUS at 30 or $80 \mathrm{~mW} / \mathrm{cm}^{2}$ for 5 days. After 28 days, LIPUS significantly prevented the decrease of cross-sectional area of muscle fiber and promoted the quality of gastrocnemius muscle. In addition, LIPUS significantly inhibited the content of MSTN in the serum and gastrocnemius muscle of hind limb rats, and its receptor, and promoted myoblast $\mathrm{C} 2 \mathrm{C} 12$ proliferation, promoted the stability of alanine, aspartate and glutamate metabolism pathway. These results suggest that the key mechanism of LIPUS in preventing muscle atrophy induced by hind limb unloading may be through inhibiting MSTN and stabilizing alanine, aspartate and glutamate metabolism.

\section{Introduction}

In the long-term lack of mechanical stimulation, the size, strength, volume and cross-sectional area of skeletal muscle will be significantly reduced. Due to the influence of microgravity environment, the weight of limb skeletal muscle of astronauts in space flight for a long time will be reduced[1, 2],among which the loss proportion of lower limb skeletal muscle is greater, and the mass loss speed of gastrocnemius muscle is faster [1]. In addition, muscle strength will be significantly decreased [3-7].Muscle atrophy can also be observed in long-term bedridden patients. For example, paralysis patients will have $6-40 \%$ muscle mass reduction[8], resulting in muscle strength unable to recover, affecting activities of daily living[9]. It is projected that in 2050, $20 \%$ of the world's population over 60 will suffer from sarcopenia and by 2150 , this percentage will increase to $33 \%$ of the population[10]. Muscular atrophy is associated with metabolic abnormalities, including changes in insulin sensitivity, increased fat and connective tissue infiltration in skeletal muscle, decreased hormone levels, decreased mitochondrial activity, resulting in impaired oxidative defense, and severe bone loss resulting in osteoporosis $[11,12]$.

Low intensity pulsed ultrasound (LIPUS) is a kind of low-intensity physical therapy, which has been widely proved to have a positive effect on bone healing. Because of its noninvasive and targeted characteristics, it is gradually applied, especially in clinical auxiliary stimulation of tissue regeneration[13]. Our previous studies have reported that LIPUS can significantly promote exerciseinduced muscle hypertrophy and improve muscle atrophy caused by type 1 diabetes[14].In addition, LIPUS was reported to active the proliferation of myoblasts[15]. In addition, under different frequency and 
intensity of low intensity pulsed ultrasound stimulation, it can be concluded that $3 \mathrm{MHz}$ and $1 \mathrm{~W} / \mathrm{cm}^{2}$ stimulation can promote cell proliferation to the maximum extent. At $500 \mathrm{~mW} / \mathrm{cm}^{2}, 1 \mathrm{MHz}$ stimulation maximized differentiation and subsequent multinucleated myotubes[16].However, the issue about whether LIPUS can improve muscle atrophy caused by tail suspension and its mechanisms not clear[14, 17].

Metabonomics is a new method to describe small molecules in organisms, cells and tissues. Since metabolites represent the downstream expression of genome, transcriptome and proteome, it is most beneficial to study them for disease risk and phenotypic changes and endogenous variation[18].In the aging model of muscle atrophy, the type of fast muscle fiber involved in glycolysis will decrease rapidly[19].A shift in fuel metabolism from lipid fuels to glucose has been found in models of space flight[20], hind limb suspension[21], bed rest and aging[22, 23]. In addition, the accumulation of triglycerides in atrophic muscles was also found [24-26]. Phospholipids in skeletal muscle also change during atrophy[27]Some studies have reported the changes of metabolites, such as amino acids, intermediate products of TCA cycle and oxidative stress markers in skeletal muscle[28, 29]. However, the effect of LIPUS on the metabonomics of muscle atrophy has not been reported.

In this study, we investigate the effects of LIPUS on muscle atrophy in tail suspended rats, andanalyze the underlying mechanism from the perspective of metabonomics. Besides, myostatin (MSTN), a key negativeregulatorof muscle growth and development, which has strong catabolic and anti anabolic effects on skeletal muscle was also evaluated.

\section{Methods}

\section{Animals}

Forty-eight male Sprague Dawley rats (180-220 g) were obtained from the Laboratory Animal Breeding and Research Center of Xi'an Jiaotong University (Xi'an, China) and were housed in a controlled room (22 $\pm 2{ }^{\circ} \mathrm{C}, 60 \pm 5 \%$ humidity, and 12-h light/dark cycle). All experiments were conducted with the approval of the Animal Ethical Committee of Shaanxi Normal University and in accordance with the Guide for the Care and Use of Laboratory Animals published by the US National Institutes of Health (NIH publication no. 85-23, revised 1996).

\section{Animal modeling and grouping}

In this study, the model of muscle atrophy was induced by unloading the hind limbs of rats[30]. The tail of the rats was suspended, and the body was at an angle of $30^{\circ}$ with the ground. The forelimbs could move freely in the cage. During the experiment, they could eat and drink water freely. The rats were randomly divided into 4 groups: normal control group $(N C, n=8)$, hind limb unloading group $(U L, n=8), 30$ 
$\mathrm{mW} / \mathrm{cm}^{2}$ LIPUS irradiation group $\left(\mathrm{UL}+30 \mathrm{~mW} / \mathrm{cm}^{2}, \mathrm{n}=8\right), 80 \mathrm{~mW} / \mathrm{cm}^{2}$ LIPUS irradiation group (UL +80 $\left.\mathrm{mW} / \mathrm{cm}^{2}, \mathrm{n}=8\right)$.

\section{LIPUS irradiation}

The LIPUS equipment was self-developed and self-manufactured by the Shaanxi Key Laboratory of Ultrasonics (Shaanxi Normal University, Xi'an, China). After shaving, the gastrocnemius of tail suspended rats were irradiated with LIPUS for $28 \mathrm{~d}$. The LIPUS parameters were $30 \mathrm{~mW} / \mathrm{cm}^{2}$ and $80 \mathrm{~mW} / \mathrm{cm}^{2}$, the center frequency was $1 \mathrm{MHz}$, the duty cycle was $20 \%$, and the duration was $20 \mathrm{~min} / \mathrm{d}$.

\section{Sample preparation}

The weight of rats was monitored every week.After28 days of LIPUS irradiation,the rats were euthanized with an overdose of pentobarbital.Blood samples were obtained via abdominal aortapuncture, and then centrifuged at $1500 \times$ for $20 \mathrm{~min}$ at $4{ }^{\circ} \mathrm{C}$. The serum was separated and stored at $-80^{\circ} \mathrm{C}$ until analysis. The gastrocnemius muscles were harvested and weighed. The left gastrocnemius muscle of each group was stored in $4 \%$ paraformaldehyde for morphological experiment. The right gastrocnemius muscle of each group was stored in liquid nitrogen for western blot and real-time quantitative PCR.

\section{Fast and slow muscle immunofluorescence}

The muscle tissue was removed from $4 \%$ paraformaldehyde and dehydrated with sucrose solution. After frozen section, the sections were sealed with $3 \%$ BSA for 30 min, and then incubated with the first antibody (service bio, GB 112130/GB 111875, 1:3000 / 1:500) at $4{ }^{\circ} \mathrm{C}$ overnight and the fluorescent second antibody at room temperature for $50 \mathrm{~min}$ (service bio, gb21303/gb25301, 1:300/1:400). The nucleuses were dyed with DAPI (service bio, g1012). The images were taken under an inverted fluorescence microscope (Olympus Bx-51, Japan) at $\times 200$ magnification. Three fields were randomly selected in each group, and the cross-sectional area of muscle fibers was calculated by Caseviewer2.1. The average cross-sectional muscle fiber area was calculated as the total cross-sectional area/total number of muscle fibers in the visual field.

\section{Muscle tension in vivo}

The muscle tension of gastrocnemius muscle in vivo was measured by muscle test system instrument (Aurora, 1305A, Canada). Before the test, the rats were anesthetized in abdominal cavity, and the rats were supine on the rat platform in human anatomical posture, and the lower leg and thigh were 90 degrees, and the right knee was fixed with screws. The right sole of the rat's right foot was fixed on the pedal with medical adhesive tape to ensure that the fixed position of the rat's right foot would not be 
damaged by the contraction of the calf muscle during the current stimulation. Two metal electrodes were located at the nerves of gastrocnemius muscle to ensure that gastrocnemius could receive electric stimulation. The instrument runs the test program, and sends $30 \mathrm{~Hz}, 50 \mathrm{~Hz}$, and $80 \mathrm{~Hz}$ electrical stimulation to gastrocnemius muscle respectively through the electrode, so as to make the gastrocnemius muscle tension produce muscle tension, and record the corresponding gastrocnemius muscle tension under each frequency electrical stimulation, the unit is $\mathrm{mN}$. Each rat repeated the test three times, and the values were statistically analyzed.

\section{Serum MSTN analysis}

Serum level of MSTN was assessed using ELISA kits. Absorbance was measured on a Model 680 microplatereader (Bio-rad Corp, Philadelphia, PA, USA).

\section{Western blot}

Gastrocnemius muscle tissue was weighed and homogenized with 450 uL Ripa lysate. The supernatant was quantified with BCA protein quantitative kit (Thermo Scientific). The immunoblots were incubated with MSTN (ab124721) and ActrlIB (ab180185) antibodies overnight at $4{ }^{\circ} \mathrm{C}$ according to the traditional method. Finally, Image $J$ is used to process the image.

\section{RNA isolation and RT-PCR}

The total RNA of gastrocnemius muscle was isolated by geneJET RNA Purification Kit (Thermo Scientific). The cfx96 real time PCR system (Bio-Rad laboratory in Hercules, California, USA) was used to evaluate RNA integrity, and a 680 micro board reader (Bellard, Philadelphia, PA, USA) was used to quantify RNA integrity. Reverse transcription was carried out using the biological transcription Kit (Takara, Japan). The amplification procedure consisted of one cycle at $95^{\circ} \mathrm{C}$ for 1 minute, followed by 40 cycles at $94^{\circ} \mathrm{C}$ for 15 seconds, $60^{\circ} \mathrm{C}$ for 15 seconds, and $72^{\circ} \mathrm{C}$ for 30 seconds. GAPDH was normalized as a housekeeping gene. The relative expression of gene was detected by RT-PCR. All experiments were repeated at least three times. The Primers are as follows: GATTATCACGCTACCACG (forward) and ATTCAGCCCATCTTCTCC (reverse) for MSTN,GCAGTCGTGGCAGAGTGAGCG (forward) and CTTGAGGTAATCCGTGAGGGAGC (reverse) for ActrlIB

\section{Cell culture}

Mouse myoblastic cell line C2C12 cells were obtained from Xi'an Jiaotong University (Xi'an, China). The cells were cultured with Dulbecco's Modified Eagle Medium (DMEM, HyClone) containing $10 \%$ fetal bovine serum (FBS, Gibco), $100 \mathrm{U} / \mathrm{mL}$ penicillinand and $100 \mu \mathrm{g} / \mathrm{mL}$ streptomycin (1\% P/S, sigma), at $37^{\circ}$ $\mathrm{C}$ in a humid atmosphere of $5 \% \mathrm{CO} 2$. 


\section{CCK-8 detection}

The myoblast activity was tested by CCK-8 kit. After 7 days of cell culture, the working solution was prepared according to the kit instructions (100:10). After adding the test solution, the cells were incubated in the cell incubator for 2 hours. The absorbance at $450 \mathrm{~nm}$ was detected byModel 680 microplatereader (Belad, Philadelphia, PA, USA).

\section{DAPI staining}

The cells were cultured for 7 days. On day 8 , the cells were fixed with $4 \%$ paraformaldehyde and stained with anti fluorescence quenching blocking agent containing DAPI (Solarbio) for $10 \mathrm{~min}$. Take photos and count under inverted fluorescence microscope (Olympus Bx-51, Japan) at $\times 400$.

\section{Metabonomics analysis of differential metabolites and pathways}

$500 \mu \mathrm{L}$ serum was collected and stored in EP tube at $-80^{\circ} \mathrm{C}$. During detection, $100 \mu \mathrm{L}$ serum was taken, $300 \mu \mathrm{L}$ methanol and $5 \mu \mathrm{L}$ internal standard $(9.9 \mathrm{mg} / \mathrm{mL}$ ribose alcohol) were added. Vortex mixing for $30 \mathrm{~s}$ and standing at $-20^{\circ} \mathrm{C}$ for $1 \mathrm{~h}$. Centrifuge at $12000 \mathrm{rpm}$ for $10 \mathrm{~min}$ at $4^{\circ} \mathrm{C}$. $200 \mu \mathrm{L}$ supernatant was collected and dried at room temperature for derivatization: $35 \mu \mathrm{L}$ methoxypyridine solution $(20 \mathrm{mg} / \mathrm{mL})$ was subjected to strong vibration for $30 \mathrm{~s}$, then oximation reaction was carried out at $37^{\circ} \mathrm{C}$ for $90 \mathrm{~min}$, and $35 \mu \mathrm{L}$ BSTFA was added for derivatization, then reaction was carried out at $70^{\circ} \mathrm{C}$ for $60 \mathrm{~min}$, and then standing at room temperature for $30 \mathrm{~min}$. GC/MS detection and analysis: GC/MS detection adopts multivariate statistical method to analyze the principal components. Meanwhile, through the orthogonal partial least squaresdiscriminant analysis (OPLS-DA), the standard threshold for finding differential metabolites is VIP $>1$, $p$-value $<0.05$. All compounds are screened by Fiehn database for biomarkers, and the screened biomarkers are analyzed by MetPA database. Finally, the protein metabolic pathway was constructed.

\section{Statistical analysis}

Results were expressed as mean \pm SD. Statistical analysis was performed using SPSS version 20.0 (SPSS Institute, Chicago, IL, USA). Univariate analysis of variance among the four groups was performed and Tukey's multiple comparison tests was used to determine the significance between each group. $P$ values $<0.05$ were considered statistically significant.

\section{Results}

\section{Body weight and muscle weight}


Body weight and gastrocnemius weight were measured at the end of the experiment (Fig.1). Compared with NC group, both of the body weight and gastrocnemius weight in UL group, $U L+30 \mathrm{~mW} / \mathrm{cm}^{2}$ and $\mathrm{UL}+80 \mathrm{~mW} / \mathrm{cm}^{2}$ groups were significantly decreased $(p<0.01 ; p<0.01 ; p<0.05)$. Compared with UL group, gastrocnemius weight of group $\mathrm{UL}+80 \mathrm{~mW} / \mathrm{cm}^{2}$ increased significantly $(p<0.05)$.

\section{Mean cross sectional area of muscle fiber}

The averagecross sectional area of fast muscle fiber was shown in Fig. 2A. Compared with UL group, $\mathrm{UL}+80 \mathrm{~mW} / \mathrm{cm}^{2}$ group showed a significant increase $(p<0.05)$. As shown in Fig.2B, compared with ULgroup, the average cross sectionalarea of slow musclefiberinUL $+30 \mathrm{~mW} / \mathrm{cm}^{2}$ and $U L+80$ $\mathrm{mW} / \mathrm{cm}^{2}$ groupwas significantly higher $(p<0.01, p<0.01)$. The averagecross sectional area of muscle fiber was shown in Fig. 2C. Compared with NC group, UL group showed a significant decrease $(p<0.01)$.Both $30 \mathrm{~mW} / \mathrm{cm}^{2}$ and $80 \mathrm{~mW} / \mathrm{cm}^{2}$ LIPUS significantly increased the average cross sectional area of muscle fiber $(p<0.01, p<0.01)$ compared with UL group.

\section{PMuscle tension}

Muscle tension in vivo was detected (Fig.3). The results showed that all of the muscle tension in the UL, $\mathrm{UL}+80 \mathrm{~mW} / \mathrm{cm}^{2}$ and $\mathrm{UL}+30 \mathrm{~mW} / \mathrm{cm}^{2}$ group decreased significantly under different intensity of electric stimulation. Compared with UL, the muscle tension of $\mathrm{UL}+80 \mathrm{~mW} / \mathrm{cm}^{2}$ and $\mathrm{UL}+30 \mathrm{~mW} / \mathrm{cm}^{2}$ groups increased significantly, and the effect of $\mathrm{UL}+80 \mathrm{~mW} / \mathrm{cm}^{2}$ was slightly better, but not significant.

\section{Cell proliferation}

As shown in Fig. 4B. CCK-8 results showed that compared with the NC group. $30 \mathrm{~mW} / \mathrm{cm}^{2}$ and 80 $\mathrm{mW} / \mathrm{cm}^{2}$ LIPUS significantly promoted cell proliferation $(\mathrm{p}<0.01 ; \mathrm{p}<0.05)$, and the effect of $30 \mathrm{~mW} / \mathrm{cm}^{2}$ is better than that of $80 \mathrm{~mW} / \mathrm{cm}^{2}(p<0.01)$. The results showed that $30 \mathrm{~mW} / \mathrm{cm}^{2}$ LIPUS significantly increased the number of $\mathrm{C} 2 \mathrm{C} 12$ cells $(p<0.01)$, and the effect is higher than $80 \mathrm{~mW} / \mathrm{cm}^{2}(p<0.05)$. (Fig. 4C)

\section{The expressions of MSTN and its receptor}

The content of MSTN in serum is shown in Fig.5A.The serum MSTN levels in UL group, $\mathrm{UL}+30 \mathrm{~mW} / \mathrm{cm}^{2}$ group and UL+80mW/cm2 group were significantly higher than those in NC group $(p<0.01 ; p<0.01 ; p<$ 0.01). The mRNA and protein expression of MSTN in each group is shown in Figure $5 B, C$. Compared with NC group, the mRNA and protein expression UL group was significantly increased $(p<0.01 ; p<0.01)$. However, LIPUS at $30 \mathrm{~mW} / \mathrm{cm}^{2}$ and $80 \mathrm{~mW} / \mathrm{cm}^{2}$ significantly decreased the mRNA and protein expression 
of MSTN $(p<0.01 ; p<0.01)$. In addition, the MSTN mRNA expression

inUL $+80 \mathrm{~mW} / \mathrm{cm}^{2}$ groupwassignificantly lower than that in $\mathrm{UL}+30 \mathrm{~mW} / \mathrm{cm}^{2}(p<0.05)$. The mRNA level of ActRIIB is shown in 5D. There was no significant difference among the groups. The protein expression of ActRIIB is shown in Fig. 5E. The protein expression of ActRIIB in UL group was significantly higher than that in NC group $(p<0.01)$. And $80 \mathrm{~mW} / \mathrm{cm}^{2}$ LIPUS significantly down regulated its expression $(p<0.05)$.

\section{GC-MS analysis of metabolic profiling}

The stability and repeatability of GC-MS system for large-scale sample analysis were confirmed by mixed quality control sample analysis (QC) and internal standard retention time (RT). In the whole analysis process, 4 quality control samples and internal standard serum were analyzed. Principal component analysis (PCA) score chart, including all test and quality control samples, showed that the characteristics of quality control samples were closely clustered. Therefore, the stability and repeatability of the method are considered acceptable. Typical total ion chromatograms (TIC) of serum samples from NC group, UL group, $\mathrm{UL}+30 \mathrm{~mW} / \mathrm{cm}^{2}$ group and $\mathrm{UL}+80 \mathrm{~mW} / \mathrm{cm}^{2}$ group are shown in Figure 6 . Subsequently, PCA was performed to obtain a comprehensive view of metabonomics, and unsupervised multivariate data analysis was performed to visualize trends and outliers in NC group, UL group, UL $+30 \mathrm{~mW} / \mathrm{cm}^{2}$ group and $\mathrm{UL}+80 \mathrm{~mW} / \mathrm{cm}^{2}$ group. As shown in Figure 7, the score chart is not clearly separated. The permutation test is used to verify the model. $R^{2} Y$ and $Q^{2}$ of the OPLS-DA model were 0.997 and 0.588 (Figure 8), respectively, indicating that the modelwas both reliable and predictive. In order to identify the variables leading to this huge separation, the importance of variables in the projection (VIP) statistics of OPLS-DA model and $t$ test between the two groups $(P<0.05)$ was used to pre select variables. KEGG and MS library were used to analyze the metabolites by GC-MS. the metabolites must meet the conditions of VIP $>1$ and $P<0.05$. A total of 12 metabolites were identified in NC group and UL model group, 10 metabolites were produced in $\mathrm{UL}+30 \mathrm{~mW} / \mathrm{cm}^{2}$ group and UL model group, and 12 metabolites were produced in $\mathrm{UL}+80 \mathrm{~mW} / \mathrm{cm}^{2}$ group and UL model group (Table 1). Then, the path impact value is calculated through the path topology analysis with the thresholds of 0.2. Three metabolic pathways (Phenylalanine, tyrosine and tryptophan biosynthesis;Alanine, aspartate and glutamate metabolism;Glycine, serine and threonine metabolism) were selected as important metabolic pathways for UL effect (Fig. 9A), while one metabolic pathway (Alanine, aspartate and glutamate metabolism) was selected as important metabolic pathway for $\mathrm{UL}+30 \mathrm{~mW} / \mathrm{cm}^{2}$ effect (Fig. 9B). As shown in Figure 9C, two metabolic networks (Glycine, serine and threonine metabolism;Alanine, aspartate and glutamate metabolism) changed after $\mathrm{UL}+80 \mathrm{~mW} / \mathrm{cm}^{2}$.

As shown in Figure 10, the potential biomarkers of three metabolic networks (phenylalanine, tyrosine and tryptophan biosynthesis; alanine, aspartate and glutamate metabolism; glycine, serine and threonine metabolism) decreased significantly after hindlimb unloading (L-thyrosine; L-alanine; succeed; Laspartate; citric acid; L-serine) ( $p \varangle 0.05 \rrbracket p \rrbracket 0.05 \rrbracket p \rrbracket 0.05 \rrbracket p \rrbracket 0.05 \rrbracket p \rrbracket 0.01$ ). $30 \mathrm{~mW} / \mathrm{cm}^{2}$ LIPUS may improve metabolic diseases caused by alanine, aspartate and glutamate metabolism disorder by increasing L- 
aspartate and myo inositol ( $p \varangle 0.01 \rrbracket p \llbracket 0.01)$ (FIG. 11). Similarly, $80 \mathrm{~mW} / \mathrm{cm}^{2}$ LIPUS can affect the metabolic level of hind limb unloading by improving L-aspartic acid; cholesterol; glyceric acid; xylitol and myo inositol in glycine, serine and threonine metabolism and alanine, aspartate and glutamate metabolism ( $p \rrbracket 0.01 \rrbracket p \llbracket 0.05 \rrbracket p \varangle 0.05 \rrbracket p \rrbracket 0.01 \rrbracket p \rrbracket 0.01$ ) (Fig. 12). It is suggested that LIPUS can restore the imbalance metabolism of UL rats (Table 1).

\section{Disscusion}

Long term lack of microgravity can lead to skeletal muscle atrophy [31]. LIPUS can promote the differentiation of myoblasts and promote the regeneration of muscle fibers $[15,16,32]$. Therefore, we investigated whether LIPUS could improve skeletal muscle atrophy induced by hind limb unloading. It is suggested that LIPUS can improve the muscle atrophy caused by unloading of hind limbs, and then improve the skeletal muscle function. These mechanisms may be related to MSTN/ActrllB in skeletal muscle. In addition, LIPUS can improve the metabolism of atrophic rats. And in different intensity of LIPUS, the improvement way is different.

After unloading the hind limbs, the body weight and muscle weight decreased by $25-55 \%$, among which the lower limb skeletal muscle lost a larger proportion, and the gastrocnemius muscle lost faster[33, 34]. In the 115-197 day space flight, astronauts lost $17 \%$ of gastrocnemius weight, $17 \%$ of soleus weight and $10 \%$ of quadriceps weight[35]. Toshinori et al. [36] also found similar results in rats with hind limb unloading. Our experimental results showed that hind limb unloading resulted in significant weight loss and wet weight loss of gastrocnemius muscle, but $80 \mathrm{~mW} / \mathrm{cm}^{2}$ LIPUS could improve the weight of gastrocnemius muscle, which was consistent with our previous study[14].In addition to the significant decrease of body weight and muscle mass, muscle fiber cross-sectional area and fiber type also changed[37, 38].Type I fibers contract slowly and are specially used for energy metabolism. Type II fibers contract rapidly. Fiber types have different sensitivities to different pathophysiological attacks. For example, in a model of amyotrophic disease, type II fibers are more likely to be consumed than type I fibers. Or it will change from type I and type IIA to type IIB and type IIx[36]. In this study, the average muscle fiber area had significant atrophy. However, LIPUS improved this situation in varying degrees. In terms of function, a large amount of muscle strength will be significantly lost after muscle discontinuation[39]. For example, after 17 days of space flight, a 10\% decrease in skeletal muscle strength can be observed[5]. In our study, the muscle strength of rats decreased significantlyafter unloading hind limbs. LIPUS had a tendency to improve the muscle strength loss, but there was no significant difference. The effect of LIPUS on myoblast C2C12 was also evaluated. The results showed that LIPUS could significantly promote the proliferation of $\mathrm{C} 2 \mathrm{C} 12$, which was consistent with the experimental results of Imashiro et al[40]. Similar to our experiment, after stimulating C2C12 for 5 min at $3.6 \mathrm{mHz}$ center frequency, $100 \mathrm{~Hz}$ repetition rate and $27.8 \%$ duty cycle, LIPUS significantly promoted cell proliferation [41].

MSTN plays a key role in limiting skeletal muscle growth. Its targeted or naturally occurring mutations have been shown to cause muscle growth in cattle, rabbits, rats and humans in a "double" phenotype[42- 
46]. High expression of MSTN is usually found in muscle atrophy or senile muscle diseases[47-49].It has been suggested that MSTN can control muscle quality by inhibiting cell proliferation and DNA and protein synthesis of mouse myoblast $\mathrm{C} 2 \mathrm{C} 12[50]$. Under the influence of MSTN receptor, muscle atrophy may occur[51]. Marzucanassr et al. [52] found an increase in MSTN expression in the muscle of rats with hind limb unloading. In our previous hindlimb unloading model, LIPUS effectively inhibited the expression of MSTN in quadriceps femoris muscle of rats with muscular atrophy[53].Similarly, LIPUS significantly inhibited MSTN expression in type 1 diabetic rats, exercise-induced muscle hypertrophy rats and ovariectomized rats $[14,17,54]$.In this study, LIPUS also significantly inhibited the expression of MSTN and its receptor at mRNA and protein levels, which may be related to the mechanism of LIPUS improving muscle atrophy.

Ashok Kumar et al. Confirmed the up regulation of phenylalanine, tyrosine and tryptophan biosynthesis in the process of muscle cell differentiation, suggesting that these metabolites have important significance in muscle regeneration and pathology[55]. In the muscle atrophy of hind limb unloading, we found that all the substances in this metabolic network decreased significantly. In our metabolic analysis, we found that L-tyrosine, as a key metabolite, would decrease significantly due to hind limb unloading, which would affect tryptophan biosynthesis. It has been proved that the decrease of tryptophan level is related to the decrease of myocyte, and the increase of myogenic AKT1 and AKT2 will appear when tryptophan is supplemented in vitro, which creates favorable conditions for myogenic differentiation and myotube maturation[56-58].

In addition, alanine, aspartate and glutamate metabolism were also significantly affected by hind limb unloading. A significant decrease of alanine in hind limb unloading ratswas detected. A cross-sectional study concluded that low level of alanine can be used to predict low muscle strength of the elderly, and the decrease of alanine aminotransferase was detected in the blood. At the same time, the linear relationship between low muscle strength and low level of alanine amino transferase was verified [59]. Therefore, increasing the level of L-Alanine has a positive effect on promoting the growth of muscle strength. Both $30 \mathrm{~mW} / \mathrm{cm}^{2}$ and $80 \mathrm{~mW} / \mathrm{cm}^{2}$ LIPUS significantly increased the serum L-alanine level of hind limb unloading rats. In this study, we found that succinic acid as a key metabolite affects the metabolic balance, which is similar to the results of skeletal muscle metabolic abnormality model,They found that succinic acid can induce the biosynthesis of mitochondria, promote the increase of the number of mitochondria, and enhance the respiratory capacity of oxidative skeletal muscle, and proposed that the significant decrease of succinic acid content in hind limb unloading may be related to the biosynthesis[60].Aspartic acid plays a variety of functions in physiological and biological processes and is a non essential amino acid in mammals[61].Aspartic acid is used for the biosynthesis of nucleotides and proteins, and also plays an important role in skeletal muscle metabolism[62]. For example, aspartic acid supplementation can regulate muscle glucose uptake and improve muscle utilization of excess fatty acids and glycogen in rats $[63,64]$. But whether it has an impact on muscle atrophy is still being explored. In our results, hind limb unloading can lead to a significant decrease in aspartate levels. LIPUS with different sound intensities can improve muscle atrophy by promoting aspartate levels. The third pathway 
affected by hindlimb unloading was glycine, serine and threonine metabolism. In our results, the level of glycine was significantly decreased after hind limb unloading. It is consistent with our results that the glycine level in the mouse model of muscular atrophy is decreased, and glycine supplementation can maintain the muscle mass and metabolic function of the mouse model of muscular atrophy[65, 66]. Different from $30 \mathrm{~mW} / \mathrm{cm}^{2}, 80 \mathrm{~mW} / \mathrm{cm}^{2}$ also significantly improved the level of metabolites in this pathway.Some scholars have come to the conclusion that when exogenous glycine is added to myoblast $\mathrm{C} 2 \mathrm{C} 12$, the morphology of myotubes treated with glycine is larger, suggesting that increasing the utilization of glycine may help to reduce muscle consumption[67]. The effect of L-serine on muscle atrophy has not been studied, but some scholars found that serine treatment increased the expression of genes related to mitochondrial biogenesis, enhanced the quality and function of mitochondria, and improved the activity of myotubes of $\mathrm{C} 2 \mathrm{C} 12$ cells[68]. Threonine is related to muscle protein turnover and overall metabolism[69, 70]. $80 \mathrm{~mW} / \mathrm{cm}^{2}$ LIPUS can significantly promote the expression of the markers of this pathway, and the effect of $80 \mathrm{~mW} / \mathrm{cm}^{2}$ LIPUS in improving gastrocnemius atrophy is slightly better, which may be related to its improvement of two metabolic pathways.

In conclusion, this study is the first to demonstrate that LIPUS with different intensities can prevent muscle atrophy and promote myoblast proliferation by activating alanine, aspartate and glutamate metabolism and glycine, serine and threonine metabolism pathways in hind limb unloading rats. In addition, LIPUS could inhibit the expression of MSTN and its receptor during hind limb unloading. However, the exact relationship between LIPUS, MSTN and metabolic pathways still needs to be further verified. This study shows that LIPUS can be used to prevent muscle atrophy in the condition of microgravity or disuse for a long time, and can also be used as an adjuvant treatment for muscle atrophy.

\section{Declarations}

\section{Funding}

This work was supported by the National Natural Science Foundation of China (Nos. 11974233, 11727813, 11774213), the Natural Science Foundation of Shaanxi Province (2018JM1022), the Fundamental Research Funds for the Central Universities (GK202103123).

\section{Compliance with ethical standards}

All procedures were approved by the Animal Ethical Committee of Shaanxi Normal University, and carried out in accordance with the National Institutes of Health Guide for the Care and Use of Laboratory Animals (NIH Publications No. 8023, revised 1978).

\section{Availability of data and materials}


The datasets used and/or analyzed during the current study are available from the corresponding author on a reasonable request.

\section{Authors' contributions}

All authors participated in the design, interpretation of the studies, analysis of the data, and review of the manuscript. LT, LS, and JG designed the experiments. SA and ZZ conducted the experiments and performed the analysis. YZ, ZM, and XF participated in the establishment of the animal model and LIPUS treatment. JG designed the LIPUS instrument. LS and SA wrote the manuscript. All authors read and approved the final manuscript

\section{References}

1. Fitts, R.H., D.R. Riley, and J.J. Widrick, Physiology of a microgravity environment invited review: microgravity and skeletal muscle. J Appl Physiol (1985), 2000. 89(2): p. 823-39.

2. Fitts, R.H., D.R. Riley, and J.J. Widrick, Functional and structural adaptations of skeletal muscle to microgravity. J Exp Biol, 2001. 204(Pt 18): p. 3201-8.

3. Mulavara, A.P., et al., Physiological and Functional Alterations after Spaceflight and Bed Rest. Med Sci Sports Exerc, 2018. 50(9): p. 1961-1980.

4. Cohen, H.S., et al., Posturography and locomotor tests of dynamic balance after long-duration spaceflight. J Vestib Res, 2012. 22(4): p. 191-6.

5. Tesch, P.A., et al., Effects of 17-day spaceflight on knee extensor muscle function and size. Eur J Appl Physiol, 2005. 93(4): p. 463-8.

6. Shiba, N., et al., Electrically Stimulated Antagonist Muscle Contraction Increased Muscle Mass and Bone Mineral Density of One Astronaut - Initial Verification on the International Space Station. PLoS One, 2015. 10(8): p. e0134736.

7. Fitts, R.H., et al., Prolonged space flight-induced alterations in the structure and function of human skeletal muscle fibres. J Physiol, 2010. 588(Pt 18): p. 3567-92.

8. Bloomfield, S.A., Changes in musculoskeletal structure and function with prolonged bed rest. Med Sci Sports Exerc, 1997. 29(2): p. 197-206.

9. Brown, M.E., Daily activity inventory and progress record for those with atypical movement. Am J Occup Ther, 1950. 4(6): p. 261-72; contd.

10. Ali, S. and J.M. Garcia, Sarcopenia, cachexia and aging: diagnosis, mechanisms and therapeutic options - a mini-review. Gerontology, 2014. 60(4): p. 294-305.

11. Fabbri, E., et al., Aging and Multimorbidity: New Tasks, Priorities, and Frontiers for Integrated Gerontological and Clinical Research. J Am Med Dir Assoc, 2015. 16(8): p. 640-7.

12. Mitchell, W.K., et al., Sarcopenia, dynapenia, and the impact of advancing age on human skeletal muscle size and strength; a quantitative review. Front Physiol, 2012. 3: p. 260. 
13. Schofer, M.D., et al., Improved healing response in delayed unions of the tibia with low-intensity pulsed ultrasound: results of a randomized sham-controlled trial. BMC Musculoskelet Disord, 2010. 11: p. 229.

14. Tang, L., et al., Low-intensity pulsed ultrasound prevents muscle atrophy induced by type 1 diabetes in rats. Skelet Muscle, 2017. 7(1): p. 29.

15. Puts, R., et al., Activation of Mechanosensitive Transcription Factors in Murine C2C12 Mesenchymal Precursors by Focused Low-Intensity Pulsed Ultrasound (FLIPUS). IEEE Trans Ultrason Ferroelectr Freq Control, 2016. 63(10): p. 1505-1513.

16. Salgarella, A.R., et al., Optimal Ultrasound Exposure Conditions for Maximizing C2C12 Muscle Cell Proliferation and Differentiation. Ultrasound Med Biol, 2017. 43(7): p. 1452-1465.

17. Tang, L., et al., Low-Intensity Pulsed Ultrasound Promotes Exercise-Induced Muscle Hypertrophy. Ultrasound Med Biol, 2017. 43(7): p. 1411-1420.

18. Johnson, C.H., J. Ivanisevic, and G. Siuzdak, Metabolomics: beyond biomarkers and towards mechanisms. Nat Rev Mol Cell Biol, 2016. 17(7): p. 451-9.

19. Holloszy, J.O., et al., Skeletal muscle atrophy in old rats: differential changes in the three fiber types. Mech Ageing Dev, 1991. 60(2): p. 199-213.

20. Baldwin, K.M., R.E. Herrick, and S.A. McCue, Substrate oxidation capacity in rodent skeletal muscle: effects of exposure to zero gravity. J Appl Physiol (1985), 1993. 75(6): p. 2466-70.

21. Henriksen, E.J. and M.E. Tischler, Glucose uptake in rat soleus: effect of acute unloading and subsequent reloading. J Appl Physiol (1985), 1988. 64(4): p. 1428-32.

22. Ritz, P., et al., Energy and substrate metabolism during a 42-day bed-rest in a head-down tilt position in humans. Eur J Appl Physiol Occup Physiol, 1998. 78(4): p. 308-14.

23. Cartee, G.D., Aging skeletal muscle: response to exercise. Exerc Sport Sci Rev, 1994. 22: p. 91-120.

24. Blanc, S., et al., Energy and water metabolism, body composition, and hormonal changes induced by 42 days of enforced inactivity and simulated weightlessness. J Clin Endocrinol Metab, 1998. 83(12): p. $4289-97$.

25. Lane, H.W., Energy requirements for space flight. J Nutr, 1992. 122(1): p. 13-8.

26. Musacchia, X.J., et al., Skeletal muscle atrophy in response to 14 days of weightlessness: vastus medialis. J Appl Physiol (1985), 1992. 73(2 Suppl): p. 44S-50S.

27. Senoo, N., et al., PGC-1alpha-mediated changes in phospholipid profiles of exercise-trained skeletal muscle. J Lipid Res, 2015. 56(12): p. 2286-96.

28. Der-Torossian, H., et al., Metabolic derangements in the gastrocnemius and the effect of Compound A therapy in a murine model of cancer cachexia. J Cachexia Sarcopenia Muscle, 2013. 4(2): p. 14555.

29. Tseng, Y.C., et al., Preclinical Investigation of the Novel Histone Deacetylase Inhibitor AR-42 in the Treatment of Cancer-Induced Cachexia. J Natl Cancer Inst, 2015. 107(12): p. djv274. 
30. Caron, A.Z., et al., A novel hindlimb immobilization procedure for studying skeletal muscle atrophy and recovery in mouse. J Appl Physiol (1985), 2009. 106(6): p. 2049-59.

31. Mirzoev, T.M., Skeletal Muscle Recovery from Disuse Atrophy: Protein Turnover Signaling and Strategies for Accelerating Muscle Regrowth. Int J Mol Sci, 2020. 21(21).

32. Ikeda, K., et al., Effects of low-intensity pulsed ultrasound on the differentiation of C2C12 cells. Life Sci, 2006. 79(20): p. 1936-43.

33. Anderson, J.E., A. Zhu, and T.M. Mizuno, Nitric oxide treatment attenuates muscle atrophy during hind limb suspension in mice. Free Radic Biol Med, 2018. 115: p. 458-470.

34. Rossignoli, C.P., et al., Effects of intermittent dietary supplementation with conjugated linoleic acid and fish oil (EPA/DHA) on body metabolism and mitochondrial energetics in mice. J Nutr Biochem, 2018. 60: p. 16-23.

35. LeBlanc, A., et al., Muscle volume, MRI relaxation times (T2), and body composition after spaceflight. J Appl Physiol (1985), 2000. 89(6): p. 2158-64.

36. Yoshihara, T., et al., Exercise preconditioning attenuates hind limb unloading-induced gastrocnemius muscle atrophy possibly via the HDAC4/Gadd45 axis in old rats. Exp Gerontol, 2019. 122: p. 34-41.

37. Sandona, D., et al., Adaptation of mouse skeletal muscle to long-term microgravity in the MDS mission. PLoS One, 2012. 7(3): p. e33232.

38. Campione, M., et al., Myosin and troponin changes in rat soleus muscle after hindlimb suspension. $\mathrm{J}$ Appl Physiol (1985), 1993. 74(3): p. 1156-60.

39. Voet, N.B., et al., Strength training and aerobic exercise training for muscle disease. Cochrane Database Syst Rev, 2019. 12: p. CD003907.

40. Imashiro, C., et al., Detachment of cell sheets from clinically ubiquitous cell culture vessels by ultrasonic vibration. Sci Rep, 2020. 10(1): p. 9468.

41. Wolfson, R.L. and D.M. Sabatini, The Dawn of the Age of Amino Acid Sensors for the mTORC1 Pathway. Cell Metab, 2017. 26(2): p. 301-309.

42. McPherron, A.C., A.M. Lawler, and S.J. Lee, Regulation of skeletal muscle mass in mice by a new TGF-beta superfamily member. Nature, 1997. 387(6628): p. 83-90.

43. McPherron, A.C. and S.J. Lee, Double muscling in cattle due to mutations in the myostatin gene. Proc Natl Acad Sci U S A, 1997. 94(23): p. 12457-61.

44. Lv, Q., et al., Efficient Generation of Myostatin Gene Mutated Rabbit by CRISPR/Cas9. Sci Rep, 2016. 6: p. 25029.

45. Gu, H., et al., Establishment and phenotypic analysis of an Mstn knockout rat. Biochem Biophys Res Commun, 2016. 477(1): p. 115-122.

46. Schuelke, M., et al., Myostatin mutation associated with gross muscle hypertrophy in a child. N Engl J Med, 2004. 350(26): p. 2682-8.

47. Bataille, S., et al., Myostatin and muscle atrophy during chronic kidney disease. Nephrol Dial Transplant, 2020. 
48. Kobayashi, M., et al., Myostatin deficiency not only prevents muscle wasting but also improves survival in septic mice. Am J Physiol Endocrinol Metab, 2021. 320(1): p. E150-E159.

49. Lee, S.J., et al., Targeting myostatin/activin A protects against skeletal muscle and bone loss during spaceflight. Proc Natl Acad Sci U S A, 2020. 117(38): p. 23942-23951.

50. Artaza, J.N., et al., Endogenous expression and localization of myostatin and its relation to myosin heavy chain distribution in C2C12 skeletal muscle cells. J Cell Physiol, 2002. 190(2): p. 170-9.

51. Latres, E., et al., Myostatin blockade with a fully human monoclonal antibody induces muscle hypertrophy and reverses muscle atrophy in young and aged mice. Skelet Muscle, 2015. 5: p. 34.

52. Marzuca-Nassr, G.N., et al., Short-term creatine supplementation changes protein metabolism signaling in hindlimb suspension. Braz J Med Biol Res, 2019. 52(10): p. e8391.

53. Tang, L., et al., MSTN is a key mediator for low-intensity pulsed ultrasound preventing bone loss in hindlimb-suspended rats. Bone, 2021. 143: p. 115610.

54. Tang, L., et al., Inhibition of MSTN signal pathway may participate in LIPUS preventing bone loss in ovariectomized rats. J Bone Miner Metab, 2020. 38(1): p. 14-26.

55. Kumar, A., et al., Metabolomic analysis of primary human skeletal muscle cells during myogenic progression. Sci Rep, 2020. 10(1): p. 11824.

56. Braidy, N., et al., Changes in kynurenine pathway metabolism in the brain, liver and kidney of aged female Wistar rats. FEBS J, 2011. 278(22): p. 4425-34.

57. Caballero, B., R.E. Gleason, and R.J. Wurtman, Plasma amino acid concentrations in healthy elderly men and women. Am J Clin Nutr, 1991. 53(5): p. 1249-52.

58. Dukes, A., et al., The aromatic amino acid tryptophan stimulates skeletal muscle IGF1/p70s6k/mTor signaling in vivo and the expression of myogenic genes in vitro. Nutrition, 2015. 31(7-8): p. 1018-24.

59. Chung, S.M., et al., Low alanine aminotransferase levels predict low muscle strength in older patients with diabetes: A nationwide cross-sectional study in Korea. Geriatr Gerontol Int, 2020. 20(4): p. 271276.

60. Ives, S.J., et al., The effect of succinic acid on the metabolic profile in high-fat diet-induced obesity and insulin resistance. Physiol Rep, 2020. 8(21): p. e14630.

61. Corpeleijn, W.E., et al., Almost all enteral aspartate is taken up in first-pass metabolism in enterally fed preterm infants. Clin Nutr, 2010. 29(3): p. 341-6.

62. Sullivan, L.B., et al., Supporting Aspartate Biosynthesis Is an Essential Function of Respiration in Proliferating Cells. Cell, 2015. 162(3): p. 552-63.

63. Lancha, A.H., Jr., J.R. Poortmans, and L.O. Pereira, The effect of 5 days of aspartate and asparagine supplementation on glucose transport activity in rat muscle. Cell Biochem Funct, 2009. 27(8): p. 5527.

64. Lancha, A.H., Jr., et al., Effect of aspartate, asparagine, and carnitine supplementation in the diet on metabolism of skeletal muscle during a moderate exercise. Physiol Behav, 1995. 57(2): p. 367-71. 
65. Giesbertz, P., et al., Metabolite profiling in plasma and tissues of ob/ob and $d b / d b$ mice identifies novel markers of obesity and type 2 diabetes. Diabetologia, 2015. 58(9): p. 2133-43.

66. Ham, D.J., et al., Glycine administration attenuates skeletal muscle wasting in a mouse model of cancer cachexia. Clin Nutr, 2014. 33(3): p. 448-58.

67. Caldow, M.K., et al., Glycine Protects Muscle Cells From Wasting in vitro via mTORC1 Signaling. Front Nutr, 2019. 6: p. 172.

68. Sim, W.C., et al., Activation of SIRT1 by L-serine increases fatty acid oxidation and reverses insulin resistance in C2C12 myotubes. Cell Biol Toxicol, 2019. 35(5): p. 457-470.

69. Wu, G., Amino acids: metabolism, functions, and nutrition. Amino Acids, 2009. 37(1): p. 1-17.

70. Lu, Y., et al., Systemic and Metabolic Signature of Sarcopenia in Community-Dwelling Older Adults. J Gerontol A Biol Sci Med Sci, 2020. 75(2): p. 309-317.

\section{Table}

Table 1 is not available in this version of the manuscript.

\section{Figures}
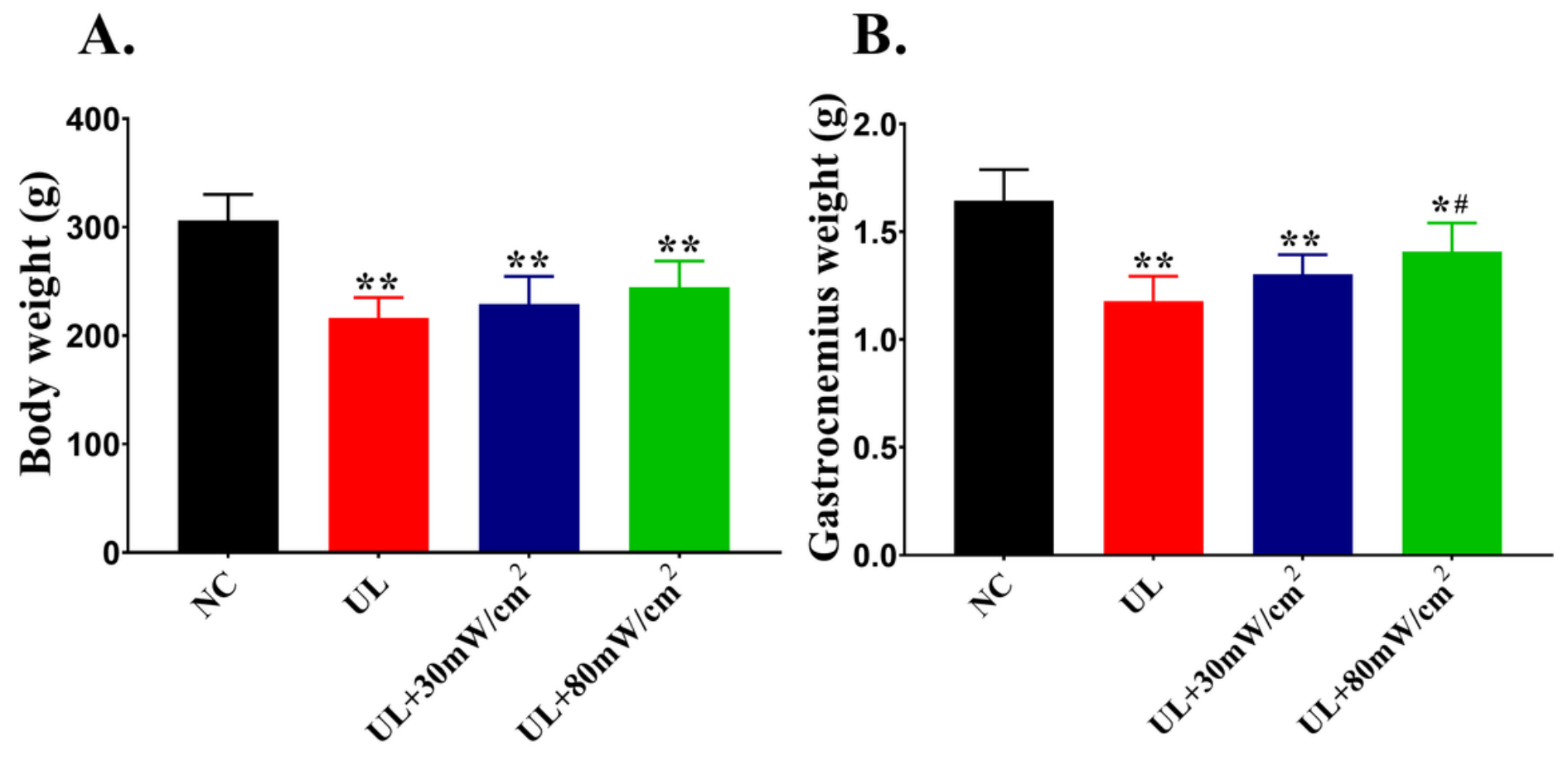

Figure 1

(A) After unloading the hind limbs, the weight of rats decreased significantly. (B) During the unloading process, the weight of gastrocnemius muscle was significantly reduced and $80 \mathrm{~mW} / \mathrm{cm} 2$ LIPUS 
significantly increased the weight of gastrocnemius muscle. The data were expressed as mean $\pm S D(n=$ 8 in each group), ${ }^{*} \mathrm{P}<0.01$ vs. NC group, ${ }^{*}<0.05$ vs. NC group, $\# \mathrm{P}<0.05$ vs. UL group.

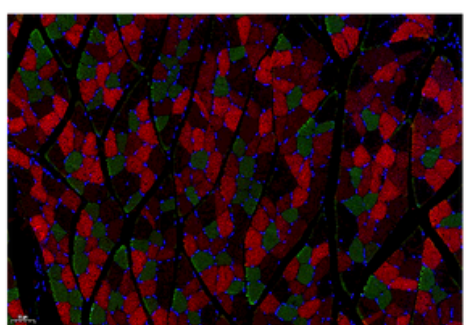

$\mathrm{NC}$

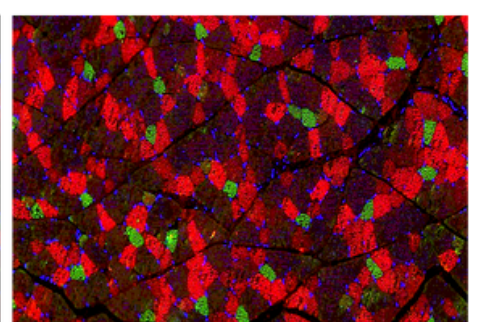

UL

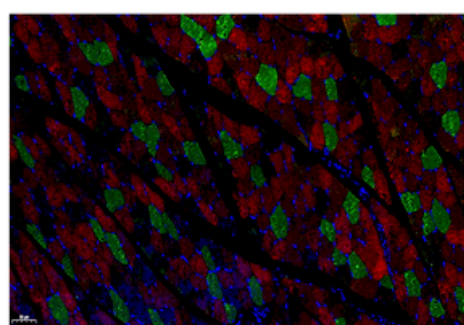

$\mathrm{UL}+30 \mathrm{~mW} / \mathrm{cm}^{2}$

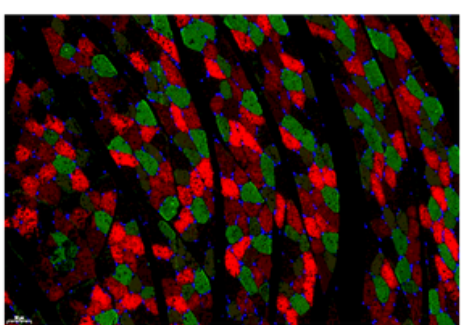

$\mathrm{UL}+80 \mathrm{~mW} / \mathrm{cm}^{2}$
A.

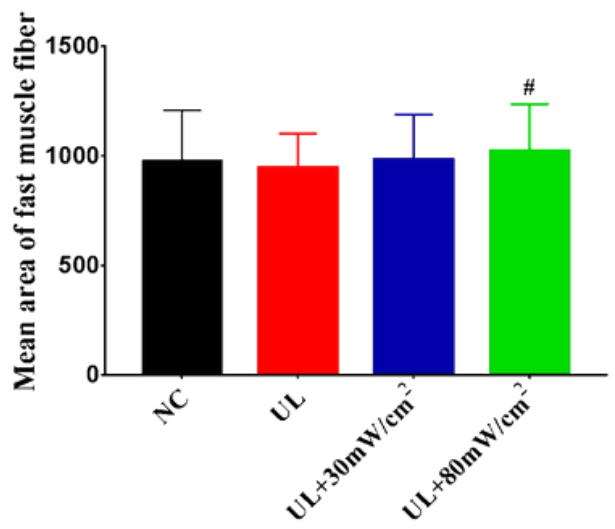

B.

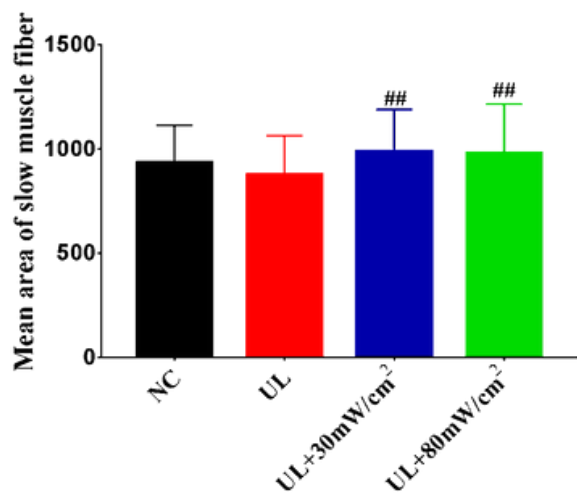

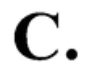

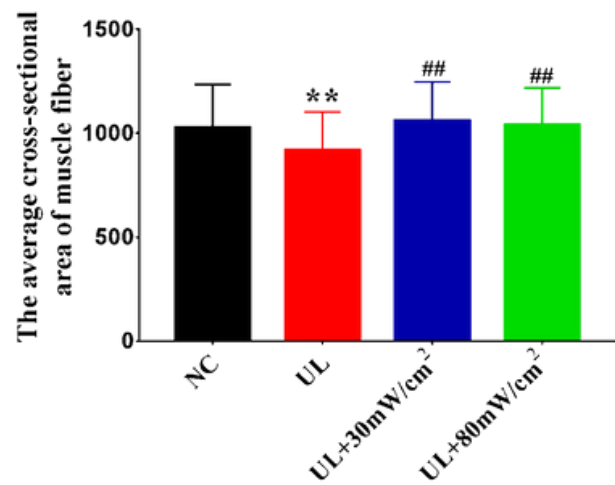

Figure 2

(A) After unloading the hind limb, $80 \mathrm{~mW} / \mathrm{cm} 2$ LIPUS significantly increased the average cross-sectional area of fast muscle fibers. (B) $30 \mathrm{~mW} / \mathrm{cm} 2$ and $80 \mathrm{~mW} / \mathrm{cm} 2$ LIPUS significantly increased the average cross-sectional area of slow muscle fibers. (C) The mean area of gastrocnemius muscle fiber decreased significantly after hind limb unloading, and LIPUS could significantly promote the mean area of gastrocnemius muscle fiber. The data were expressed as mean $\pm S D\left(n=8\right.$ in each group), ${ }^{\star *} P<0.01$ vs. NC group, \#\#P<0.01 vs. UL group, \#P<0.05 vs. UL group. 


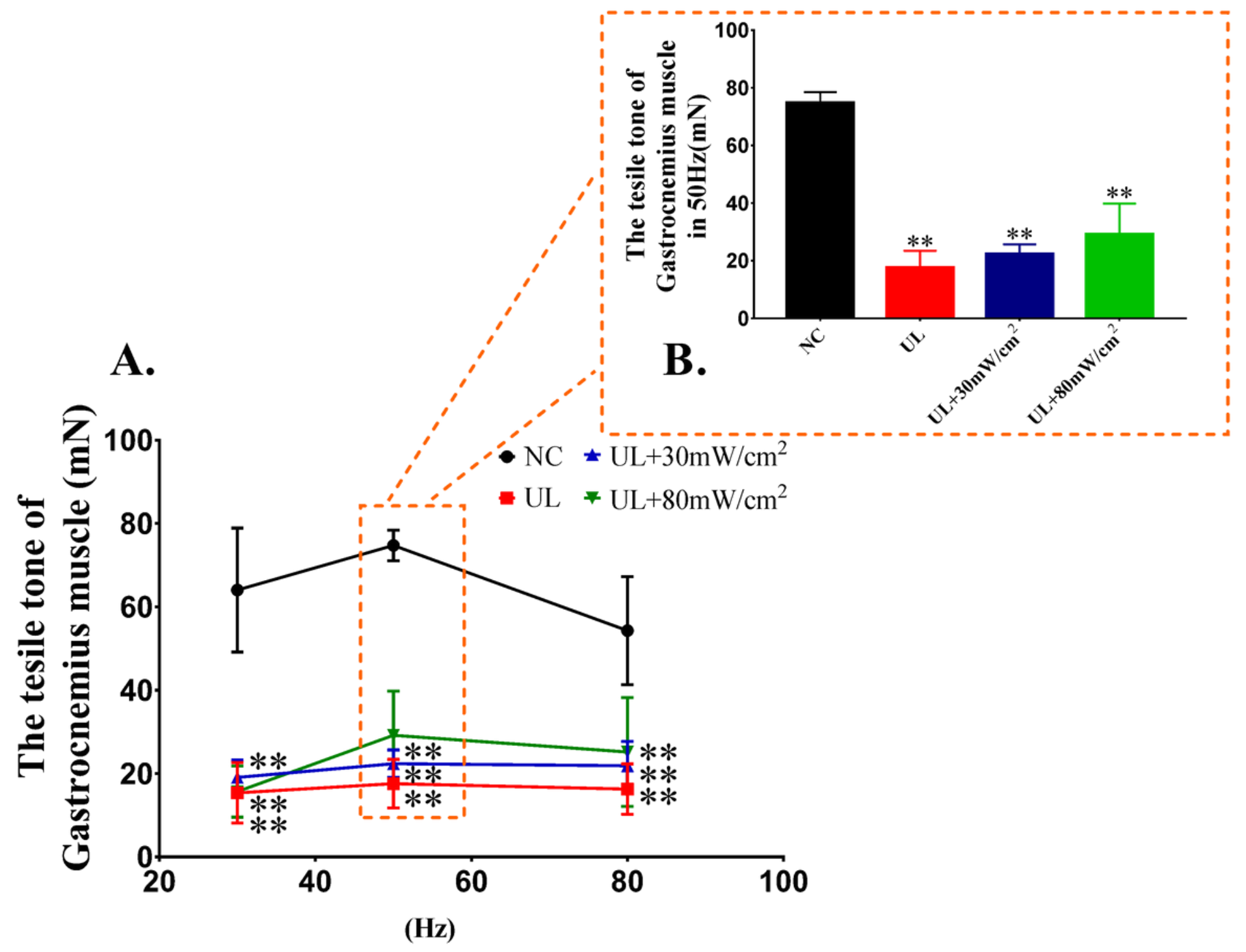

Figure 3

(A) The muscle tension of gastrocnemius muscle of hind limb unloading rats decreased significantly when stimulated at 30,50 and $80 \mathrm{~Hz}$. (B) The muscle tension of rats stimulated by $50 \mathrm{~Hz}$. The data were expressed as mean $\pm S D$ ( $n=8$ in each group), ${ }^{\star *} \mathrm{P}<0.01$ vs. NC group. 
A.
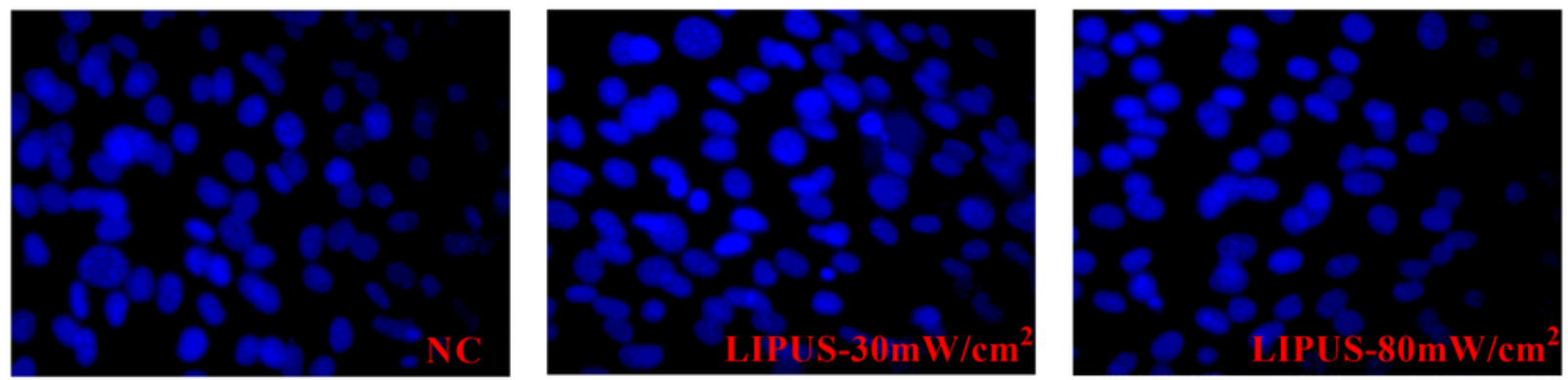

B.

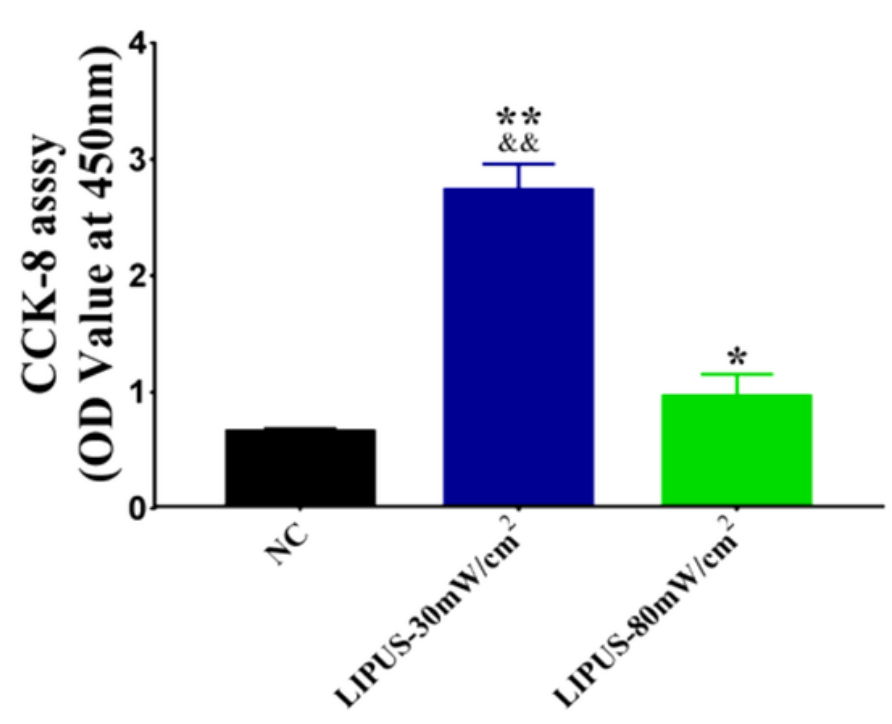

C.

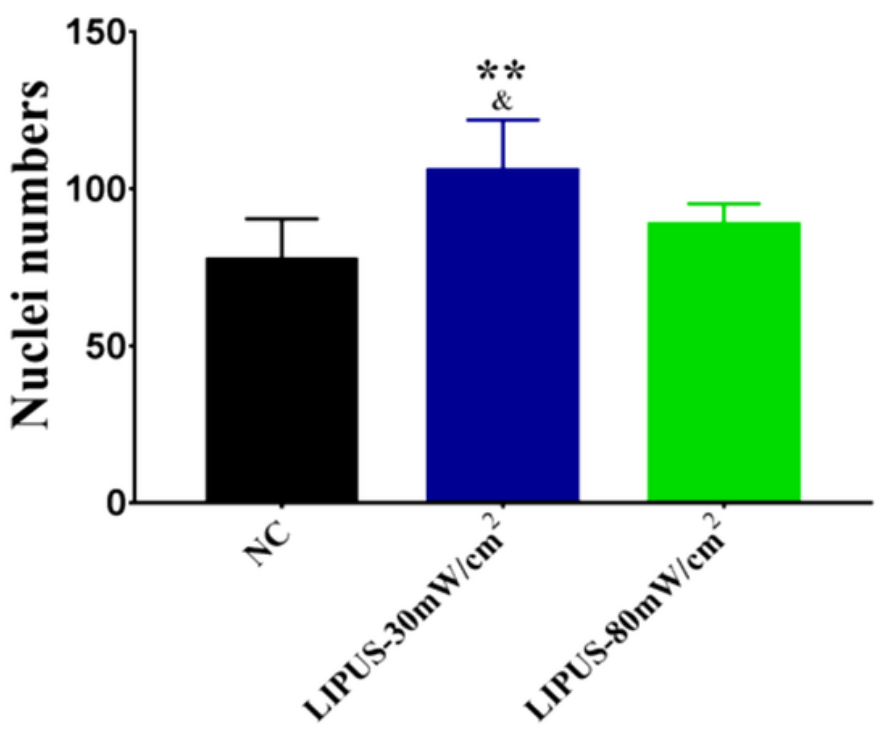

Figure 4

(A) DAPI staining of myoblasts C2C12 stimulated by LIPUS of different intensities. (B) $30 \mathrm{~mW} / \mathrm{cm} 2$ and $80 \mathrm{nmW} / \mathrm{cm} 2$ LIPUS significantly promoted the proliferation of $\mathrm{C} 2 \mathrm{C} 12$ myoblasts. (C) $30 \mathrm{~mW} / \mathrm{cm} 2$ and $80 \mathrm{~mW} / \mathrm{cm} 2 \mathrm{LIPUS}$ significantly increased the number of nuclei of $\mathrm{C} 2 \mathrm{C} 12$ myoblasts. The data were expressed as mean $\pm S D$ ( $n=8$ in each group), ${ }^{\star} * P<0.01$ vs. NC group, ${ }^{*}<<0.05$ vs. NC group, $\& \& P<0.01$ vs. $80 \mathrm{~mW} / \mathrm{cm} 2$ group, $\& \mathrm{P}<0.05 \mathrm{vs} .80 \mathrm{~mW} / \mathrm{cm} 2$ group. 

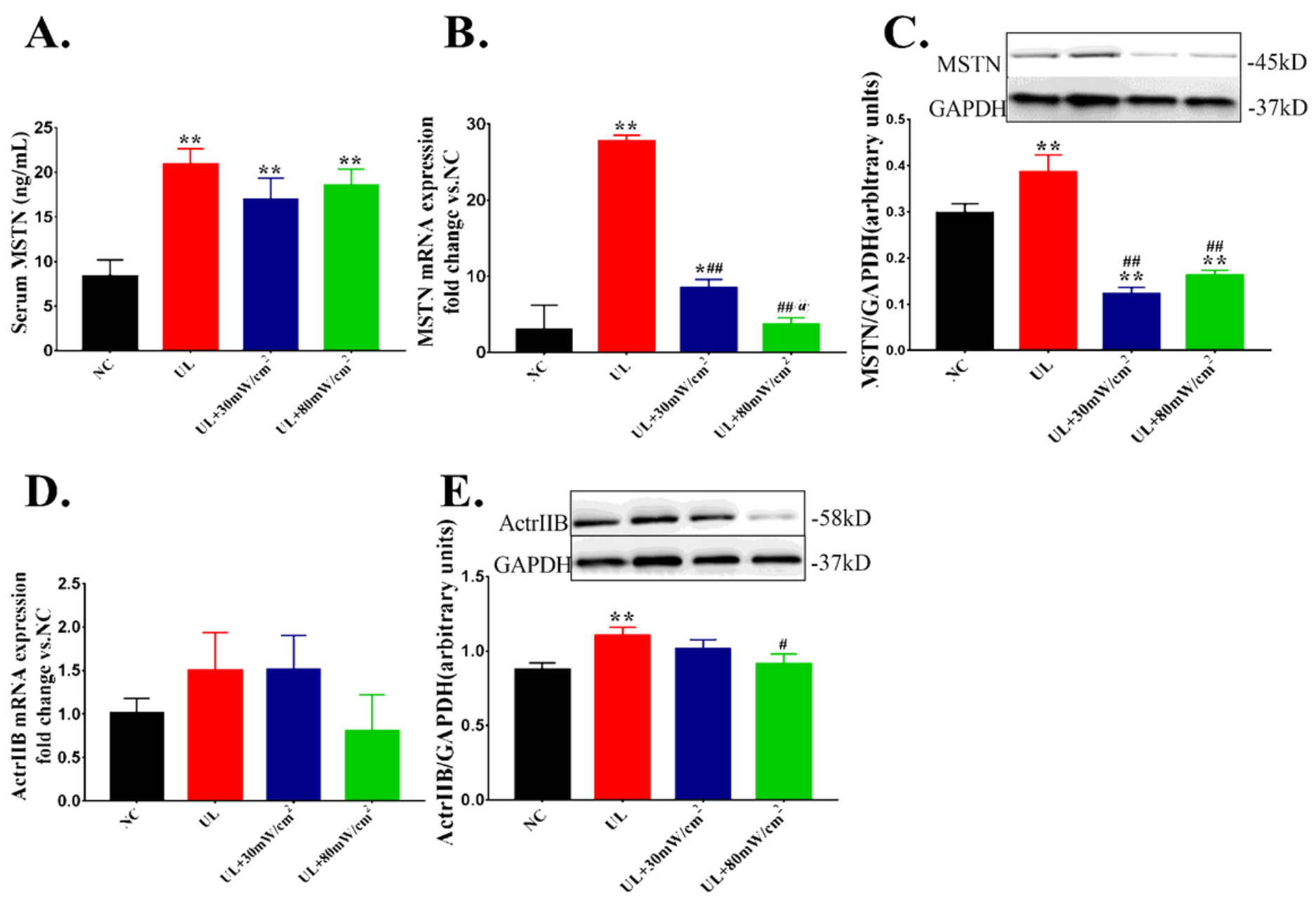

Figure 5

(A) The expression of MSTN in serum was increased significantly after hind limb unloading. (B) The mRNA level of MSTN in gastrocnemius muscle was significantly increased after hind limb unloading. The mRNA level of MSTN was significantly decreased by $30 \mathrm{~mW} / \mathrm{cm} 2$ and $80 \mathrm{~mW} / \mathrm{cm} 2$ LIPUS. (C) The protein level of MSTN in gastrocnemius muscle was significantly increased after hind limb unloading. The protein level of MSTN was significantly decreased by $30 \mathrm{~mW} / \mathrm{cm} 2$ and $80 \mathrm{~mW} / \mathrm{cm} 2$. (D) The mRNA level of $A c t r \otimes B$ in gastrocnemius muscle after hind limb unloading. ( $E)$ The protein level of Actr囚B in gastrocnemius muscle was significantly increased after hind limb unloading. The data were expressed as mean $\pm S D$ ( $n=8$ in each group), ${ }^{\star} P<0.01$ vs. NC group, ${ }^{*} P<0.05$ vs. NC group, $\# \# P<0.01$ vs. UL group, $\# P<0.05$ vs. UL group, @P<0.05 vs. $30 \mathrm{~mW} / \mathrm{cm} 2$ group. 

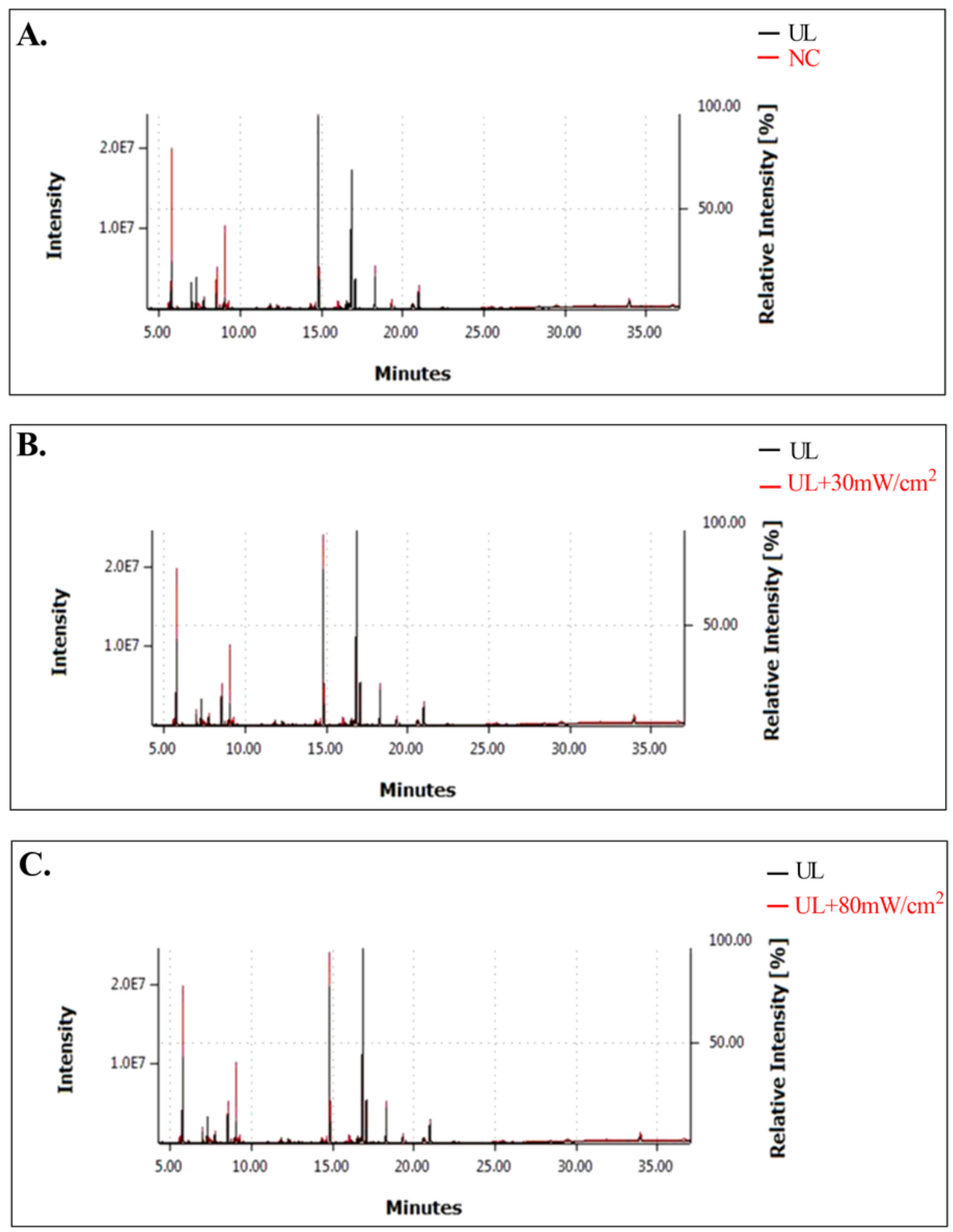

Figure 6

(A) Blood total ion flow diagram of NC and UL group. (B) Blood total ion flow diagram of UL and 30 $\mathrm{mW} / \mathrm{cm} 2$ LIPUS group. (C) Blood total ion flow diagram of UL and $80 \mathrm{~mW} / \mathrm{cm} 2$ LIPUS group. 

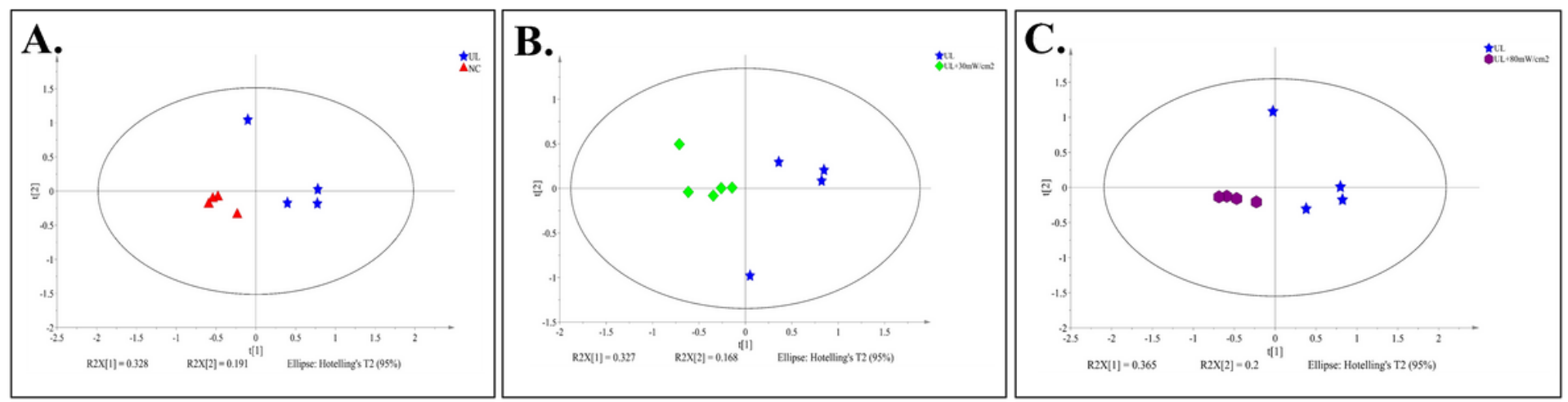

Figure 7

(A) PCA scores of UL and NC group. (B) PCA score of UL and $30 \mathrm{~mW} / \mathrm{cm} 2$ LIPUS group. (C) PCA score of UL and $80 \mathrm{~mW} / \mathrm{cm} 2$ LIPUS group.
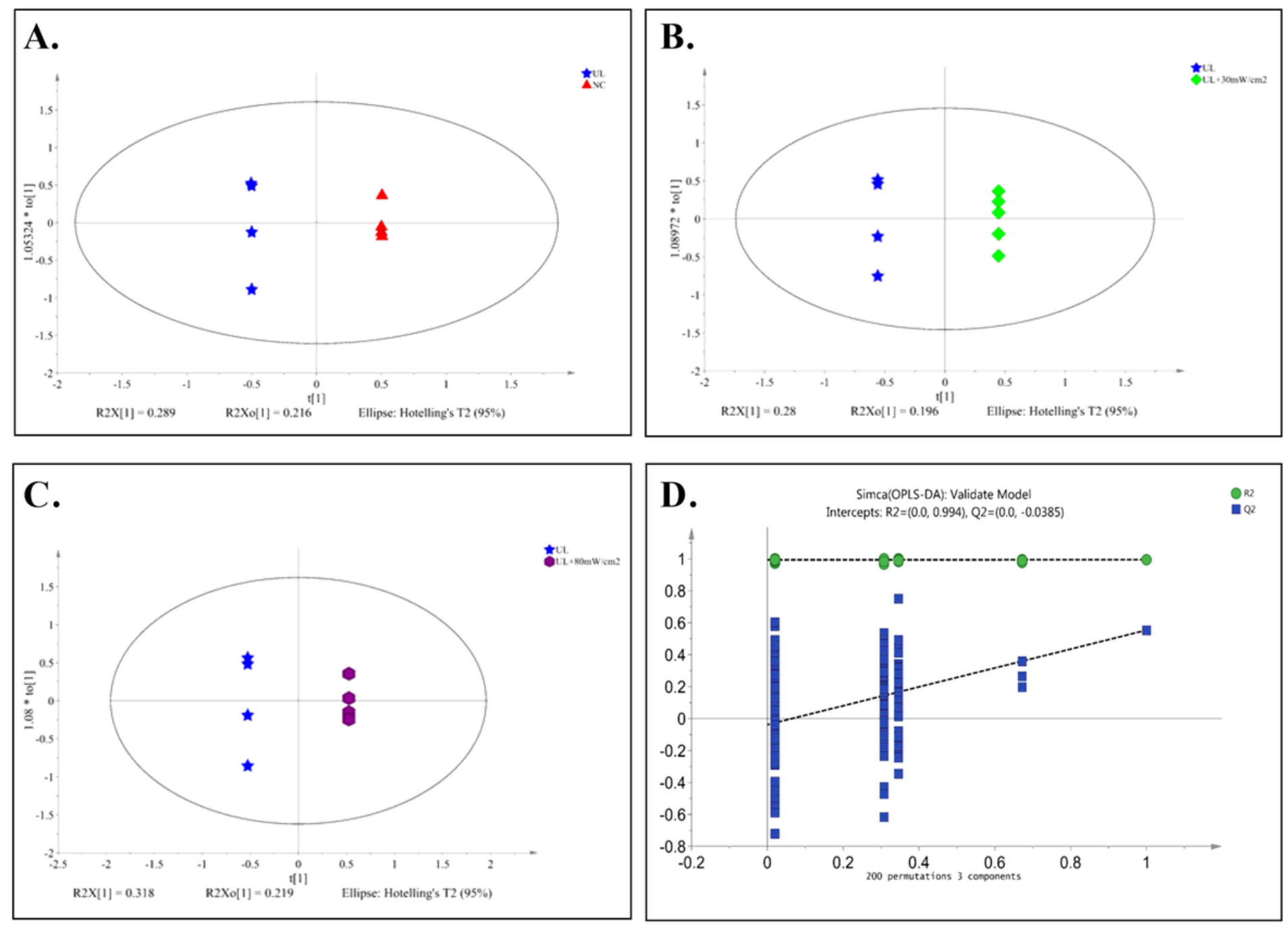

Figure 8

(A) The OPLS-DA score of UL and NC rats. (B) The OPLS-DA score chart of UL and $30 \mathrm{~mW} / \mathrm{cm} 2$ LIPUS group. (C) The scores of OPLS-DA of UL and $80 \mathrm{~mW} / \mathrm{cm} 2$ LIPUS group were compared. (D) Validation of 
OPLS-DA model of rats blood samples from four groups by permutation test (the $x$-axis means the correlation coefficient between the original $y$ variable and the permutated $y$ variable and the $y$-axis is the value of R2 and Q2).
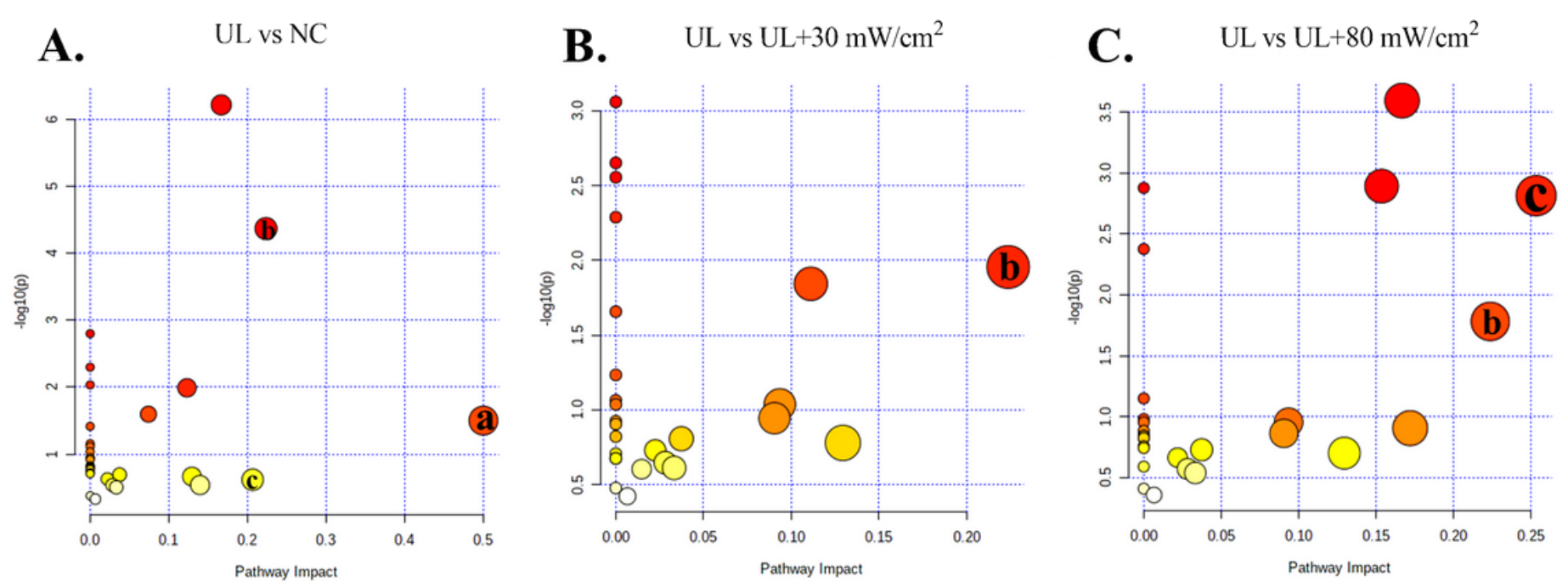

\section{Figure 9}

(A) Differential metabolic pathways between NC and UL group. (B) Differential metabolic pathways between UL and $30 \mathrm{~mW} / \mathrm{cm} 2$ LIPUS group. (C) Differential metabolic pathways between UL and 80 $\mathrm{mW} / \mathrm{cm} 2$ group. a: phenylalanine, tyrosine and tryptophan biosynthesis; b: alanine, aspartate and glutamate metabolism; c: glycine, serine and threonine metabolism.
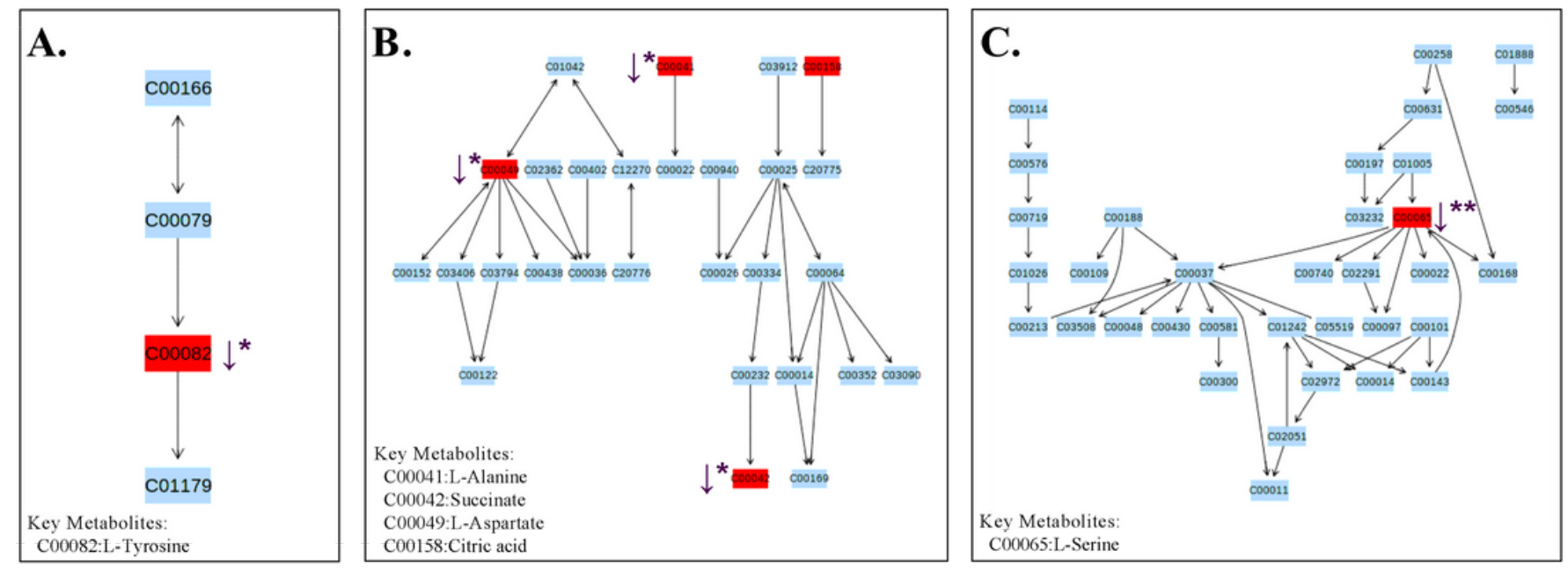

\section{Figure 10}

The different metabolic pathways between UL and NC group. A: phenylalanine, tyrosine and tryptophan biosynthesis; B: Alanine, aspartate and glutamate metabolism; C: Glycine, serine and threonine metabolism. 


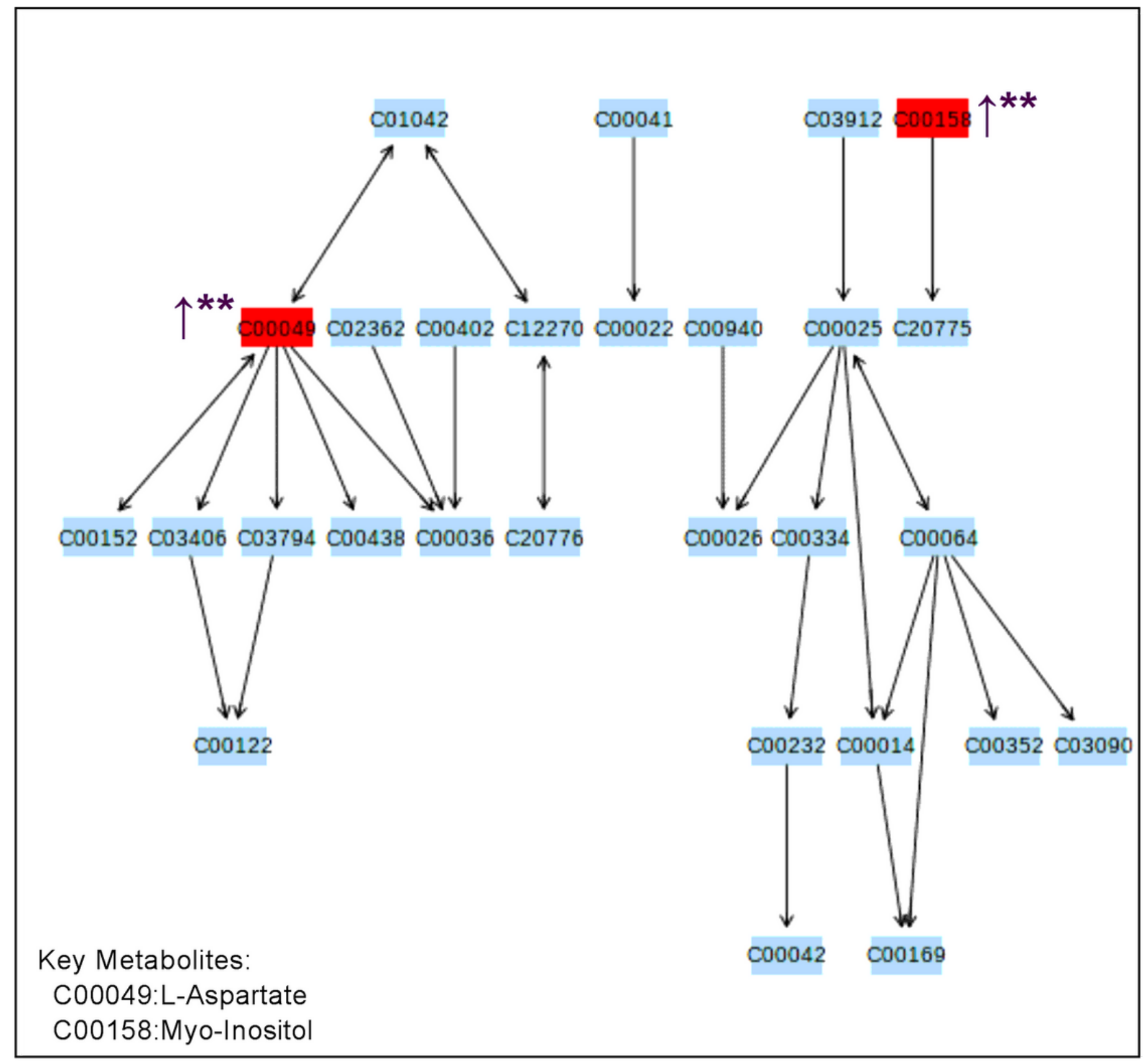

Figure 11

The different metabolic pathways between UL and $30 \mathrm{~mW} / \mathrm{cm} 2$ LIPUS group Alanine, aspartate and glutamate metabolism. 

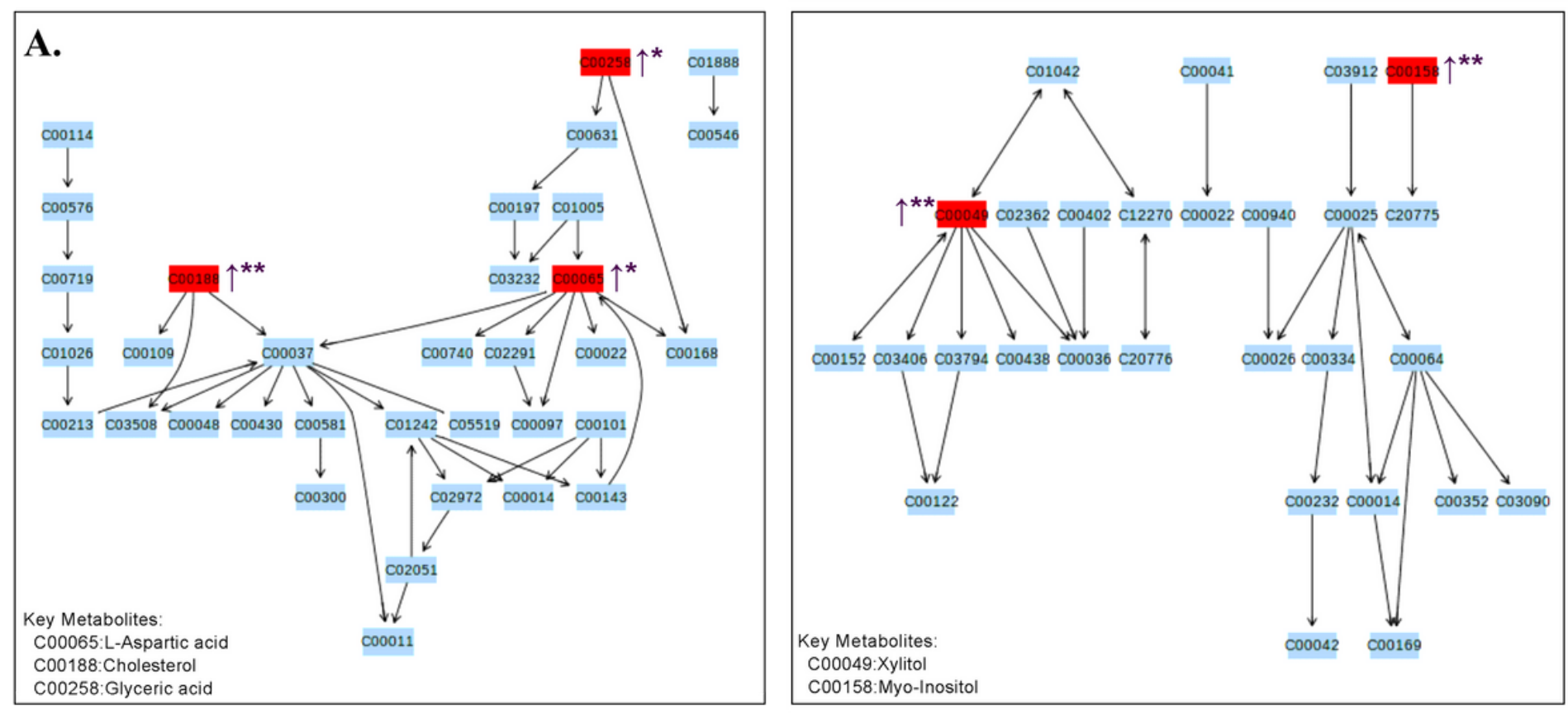

\section{Figure 12}

The different metabolic pathways between UL and $80 \mathrm{~mW} / \mathrm{cm} 2$ LIPUS group. A: Glycine, serine and threonine metabolism; B: Alanine, aspartate and glutamate metabolism. 